\title{
FLEXURAL BEHAVIOR OF BASE CONNECTION OF C-BENT COLUMN UNDER COMBINED CYCLIC BENDING-TORSIONAL LOADING
}

\author{
Mohamed A. Mohamed, Sherif S. Safar and El-Sayed B. Machaly \\ Faculty of Engineering, Cairo University, Cairo, Egypt
}

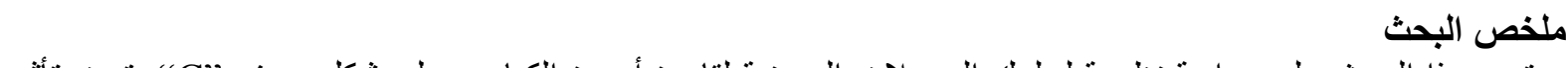

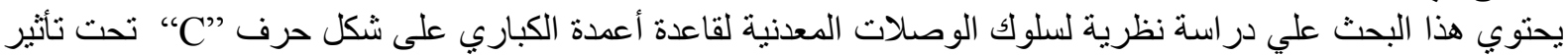

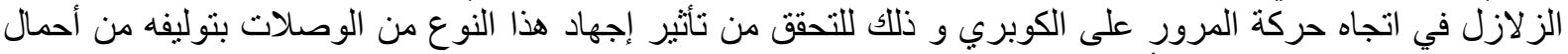

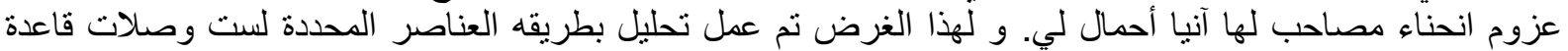

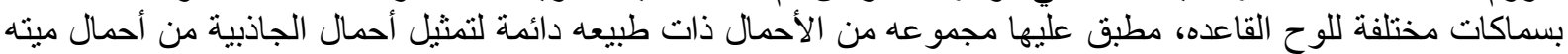

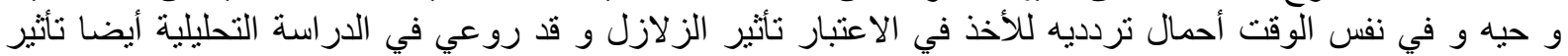

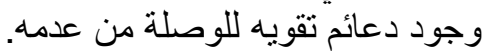

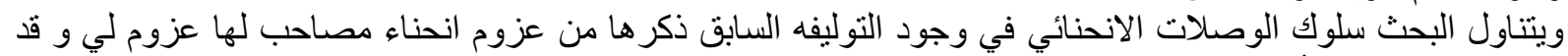

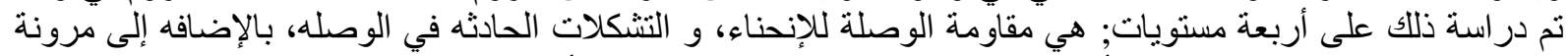

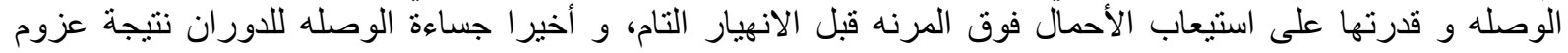

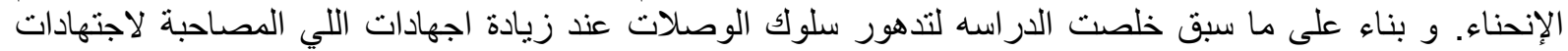
الانحناء و كذللك اهمية دعائم التقوية لتحسين سلوك الوصلاء لتهات.
\end{abstract}

\begin{abstract}
There is a lack of study concerning the torsional loading effect on the flexural response of column base especially cyclic behavior under combined torsional-flexural loading; many unknowns exist on this topic. A study for the flexural performance of the base connection for C-bent column subjected to seismic in the traffic direction is necessary to address the effect of the complex combination of cyclic flexural-torsional action on such a type of connection; for this purpose an extensive numerical parametric study was conducted to evaluate the flexural performance of the fixed base connection of C-bent bridge pier against combined cyclic bending and torsional loading following SAC phase II protocol. After verifying results with previous experimental works a Finite Element Analysis (FEA) using Strand7 is performed for Finite Element Models (FEM) which simulates force transfer at major contact interfaces in the connection, and a total of six base plate connection sub-assemblages with variable base plate thicknesses (three for stiffened connection and three for un-stiffened connection) anchored by 10 bolts, were configured and analyzed to support double cantilever pier subjected to eleven loading schemes that reflect different pairs of gravity moment and axial loads along with cyclic loading in the traffic direction eccentric from pier center of rigidity to guarantee the application of combined flexural-torsional action on the base connection. The study provided a curves for the following performance terms; strength (yield moment), deformation (yield curvature), curvature ductility, and stiffness (rotational flexural stiffness); the seismic flexural performance of the base connection under the previously mentioned loading package was evaluated by plotting the variation of the mentioned terms against the parametric values of the base plate thickness for different loading condition considered in the analysis. The study revealed that the state of gravity load weather it is concentric or eccentric has a great impact on the connection yield strength and deformation, further the level of eccentricity of the applied gravity loads has a significant impact on the connection stiffness,
\end{abstract}


more over increasing base plate thickness affect deformation capacity, and strength however with less impact on the strength and remarkable impact on the deformation, study also provided the effect of adding stiffeners to the connection, which enhanced the base fixation rigidity, however in turn of that curvature ductility has suffered noticeable reduction, in the same context curvature ductility is strongly deteriorated when the torsional stresses are dominant.

\section{KEYWORDS: C-Bent Pier, SAC Protocol, Rotation-Drift Ratio, Torsion, Gravity Loads Eccentricity, Rotational Stiffness, Curvature.}

\section{INTRODUCTION}

Column base connections are critical load path elements, transferring loads to the foundation and transmitting ground accelerations due to earthquakes to the superstructure.

Fig. 1 is a statistical analysis of over 600 steel frame buildings, compiled after the 1995 Hyogo-ken Nanbu earthquake, buildings were classified into three categories: 1) buildings built to the previous code (before the 1980 Building Standard), 2) buildings built to undefined code provisions, and 3) buildings built to the 1995 provisions. The comparison shows that column base damage was the most common form of damage in all three building categories [1].

Because of the urban areas space limitation, bridges with particular configurations, such as C-bent column bridges, skewed bridges and curved bridges, are often used. Due to their irregular structural configurations, the special seismic consideration is required to design these bridges. Since superstructure mass is eccentric from center of rigidity in C-bent columns (scope of this paper) as shown in Fig. 2, seismic forces in the traffic direction causing forces out of plan of C-bent column that induce a combination of seismic torsion and other internal forces that would result in the complex flexural and shear failure of base connection for these bridges [2]. Many researches handled the cyclic flexural behavior of the fixed base connection however there is a lack of study concerning the torsional effect on the column base especially cyclic behavior under combined torsionalflexural loading; many unknowns exist on this topic. Because of the importance of base connection and complex combination of forces mobilized on base of C-bent columns due to seismic actions; a study for the performance of the base connection for C-bent column subjected to seismic in the traffic direction is necessary to address the effect of a combined cyclic flexural-torsional action on such a type of the connection. Many researches that studied the cyclic behavior of base connection has utilized cyclic loading scheme that yields to SAC phase II loading protocol for stepwise increasing cyclic test shown in Fig. 4 that controlled by interstory drift angle which is defined by the interstory displacement divided by story height [3].

Drift capacity of strong column weak connection was investigated through a series of experiments that investigated the nonlinear, cyclic behavior of column base connections found that strong column, rigid base plate/weak anchor connections were able to accommodate drift ratios greater than 0.04 [4]. Also, at the end of the tests nonlinear rotation at the base caused for permanent deformation at the top of the column that is so hard to be straightened [5].

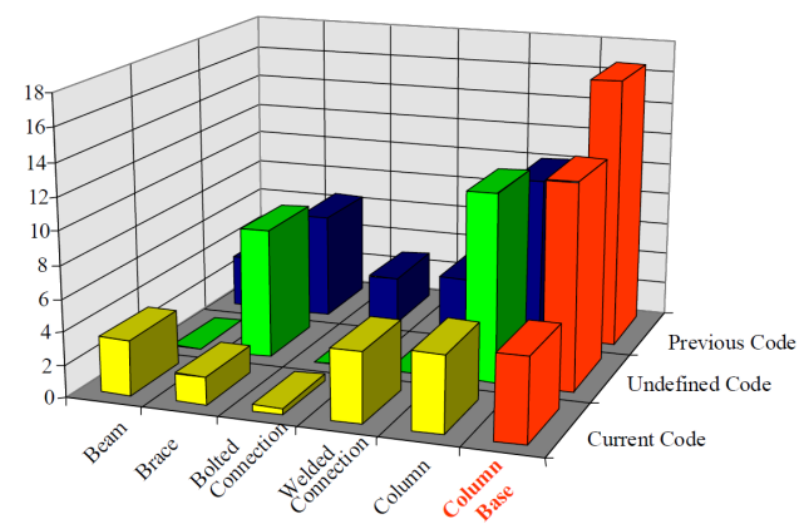

Fig. 1: Statistical analysis of the structural damage compiled after the 1995 Hyogo-ken Nanbu earthquake [1].

Many sources of deformation would contribute in the story drift of the column attached to fixed bas connection, as investigated for exposed column bases in buckling restrained braced (BRB) frames significant slip of the base plate was observed when the BRB force changed 
from compression to tension. In the design, not only the shear resistance should be checked, but also the deformations at serviceability and ultimate limit state[6]. Further experimental work has been conducted showed that the contribution of shear deformation to the overall displacement is relatively small. The fixed-end rotation of the plate and the flexural deformation of the column account for a large portion of the tip deflection in all tested connections [1].

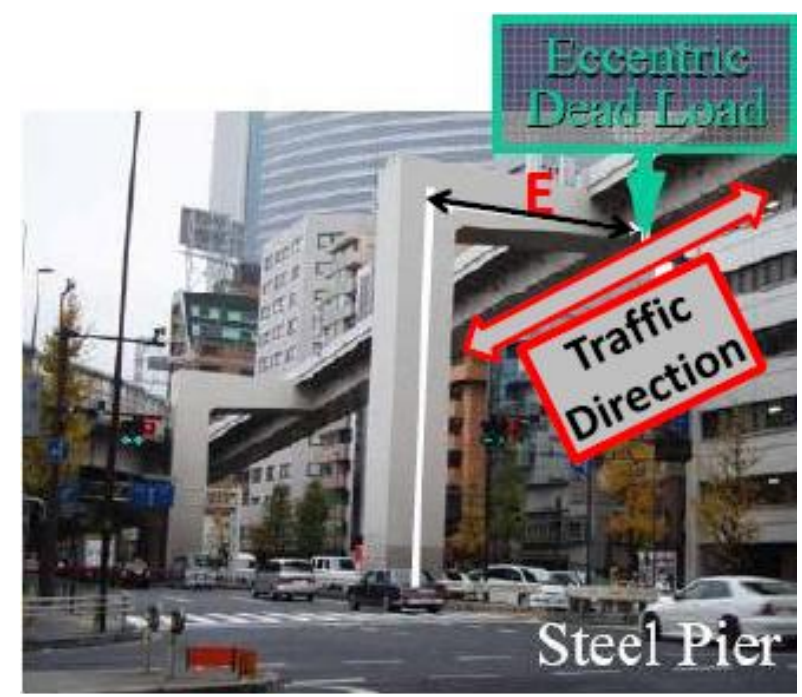

Fig. 2: Steel C-Bent Bridge Pier

From the other hand modelling technique of base connection has a significant impact on the displacement response for the numerical analysis of frame which was investigated for cablestayed bridge tower as reported in [7]; at the early time of time history response before the formation of hysteretic damping through the inelastic deformation of base connection components, the displacement peak response significantly decreases due to connection flexibility compared to fully rigid of fixed base model, while the acceleration response slightly changes with overridden acceleration spike [7].

Grade, stiffeness and detailing of anchor bolts has its impact on the base connection behavior and mobilized deformation weather in the column, or in the base plate deformed profile.

There was significant variation in the ultimate deformation capacity of the connections depending on both the anchor material used and the stretch length provided. In the level of anchor bolt elongation; increasing stretch length was found to increase the ultimate deformation capacity; however the increase was not linearly proportional to the increase in stretch length. In contrast, increases in material ductility (as measured by tensile tests) were found to lead to proportional increases in connection deformation capacity [4], This fact is emphasized as found in [5]; were the anchor bolt Grade 8.8 is not a reliable member to be designed weaker than any other base elements due to the brittle failure of high strength bolt. In order to prevent the fracture of the anchor bolts, they should be designed as strongest link of the base plate connections. If not, ductile anchor bolts should be used to prevent any brittle failure of them [5].

However in lateral deformation of bolt as recorded by [6] for exposed column bases in buckling restrained braced (BRB) frames, the anchor rods experienced large lateral deformation due to the tensile and shear force on the base plate. The interaction of shear and axial stress of the anchor rods is suggested to be considered to evaluate the maximum moment resistance of the exposed column bases in BRB frames[6].

Further study was conducted on the effect of bolt arrangement and experiments revealed that the arrangement of anchor rods controlled the maximum moment resistance of the exposed column bases in BRB frames. The slip of base plate was slightly affected by the arrangement of anchor rods [6]. In the same context a numerical analysis considered the number of bolts in exposed base plate bending about weak axis of column, this study concluded that the 4-bolt connections may cause a convex-shaped out-of-plane base plate deformation, which is resulting in very complicated base plate yielding pattern on the tension side and undesirable bearing stress concentration at the corner of the grout on the compression side. For these 
reasons, in this study, use of 6 anchor bolts is recommended as a minimum number of anchor bolts for the exposed-type column-base plate connections especially in high seismic zones [8]. Also effect of anchor post tensioning was introduced in the literature. Post tensioning of the anchor bolts can highly change the seismic performance of the column base plate connection by considerable increase of rotational stiffness and ductility [5]. However as found by numerical analysis for cable stayed tower considering the base plate flexibility, the bolt pretension force quickly vanishes through the first few cycles within the first five seconds of the time history response [7].

Many researches verified the role of the base thickness on the base connection behavior. The variation of base plate thickness has a significant effect on the strength, ductility, and stiffness of the connections. The increase of plate thickness leads to an increase in strength and rotational stiffness of the connection. An increase of plate thickness beyond that required for forming a plastic hinge in the column is inefficient since it does not change the strength or ductility of the connection [1].

Also effect of base plate thickness is extended to the contact stress distribution, where a thinner base plate can cause high local stress concentration in the anchor bolts on the tension side due to outward base plate deformation. Hence, for a selected anchor bolt size, minimum thickness of the base plate should be provided to prevent such condition in the anchor bolts before the connection reaches its ultimate state. In order to prevent undesirable early grout crushing under the base plate edge on the compression side, designing an excessively thick base plate coupled with weaker anchor bolts should be avoided [8].

One of the most important criteria of the base plate connection is its rotational stiffness which impacts the overall behaviour of the structure under seismic event as mentioned later by [7]. The rotational stiffness of the base connection suffered a considerable drop at the end of cyclic loading. So, they show higher flexibility that can increase demands of the structures in any further earthquake [5]. However for test specimens of BRB base plate connection, the moment-rotation hysteresis curve of the column base is pinched but not symmetry as that of the exposed column base in moment resisting frames [6]. From design standards aspect, column base connections designed according to US practice yield an initial rotational stiffness of 2.0 EIc/Lc regardless of the number of rods used. The value of $2.0 \mathrm{EIc} / \mathrm{Lc}$ falls between the rigid and the pinned response limits which are defined in Eurocode 3 as $25 \mathrm{EIc} / \mathrm{Lc}$ and 0.5 EIc/Lc, respectively [1].

many design procedures have proposed a scheme for the contact stress distribution beneath base plate however they needs further experimental / numerical verification. As performed in [7] when the base plate model considered connection flexibility rather than rigid model; the base lift-off is significantly large compared to concrete contact deformation; the distribution of compressive contact stresses under the base plate violates the uniformly distributed approximation [7].

Drake and Elkin (D\&E) proposed that a uniform distribution of the resultant compressive bearing stress is more appropriate when utilizing LRFD[9]. In the D\&E method, location of the resultant bearing force $(\mathrm{Ru})$ is highly dependent on the assumed value of compressive strength of concrete or grout beneath. However, results of the numerical analysis by [8] showed the opposite. The numerical parametric study revealed that location of the resultant bearing force $(\mathrm{Ru})$ as well as its amount varies with the change of the base plate thickness and anchor bolt stiffness. Thinner base plates and stiffer anchor bolts increase the amount of $\mathrm{Ru}$ due to the shortened overall moment arm between the total tensile bolt force (Tu) and $\mathrm{Ru}$ [8]. Cyclic response of base plate connection is also affected by applied actions; the level of axial force has a significant effect on the strength, ductility, and failure mode of the column base connection. Reduction of axial load beyond the design level causes an increase in the ductility and a decrease in the connection capacity [1]. Even the statistical system would impose a combination of forces that affect the base behavior as reported by [6]; the horizontal component of the BRB axial force increases the shear resistance demand of the base plate of exposed column bases. And the vertical component of the BRB axial force changes the axial force on the exposed column bases significantly [6].

Combination of applied force axial, moment, and shear can control the failure mode especially in the seismic events where the mentioned combination is variable along the duration of seismic event. It was found that the worst case for column base connection design 
would be when $\mathrm{P}=0$ based on the observation that the generated $\mathrm{P}-\mathrm{M}-\mathrm{V}$ interaction was symmetric about $\mathrm{P}=0$ plane. During earthquake generated shaking, the column might go through the load level $\mathrm{P}=0$. The authors noted that, in such cases, the column base connections should be designed for the moment and shear capacity of the column corresponding to $\mathrm{P}=0[10]$. However the dead weights have slight effects on bolt pre-tension force release [7].

\section{OBJECTIVE OF THE STUDY}

When C-Bent bridge as shown in Fig. 2 subjected to seismic action aligned with traffic direction, the CBent column and consequently its base connection will be subjected to two sets of forces in two perpendicular directions, first set is a permanent combination of axial and bending moments due to eccentric loading of gravity loading causing flexural action in the pier plan, this direction will be referred as transverse direction, and the ratio between bending and axial permanent Loads is depending on the eccentricity "E" value illustrated in Fig. 2. The other set of forces is a combined cyclic flexural-torsional stresses accompanied with cyclic shear due to seismic induced forces at center of mass eccentric from the pier center of rigidity in the direction of traffic (out of pier plan), this direction will be referred as longitudinal direction and again ratio of flexural to torsional stress is following the variation of " $\mathrm{E}$ ".

In order to simulate the above mentioned state of stresses to capture the real behavior; a numerical study using finite element analysis shall be conducted to study varieties of connection configuration with variable base plate thickness subjected to the previously mentioned two sets of forces with parametric values of " $E$ " that produces different transverse bending to axial ratios combined with cyclic loading in the longitudinal direction with multiple levels of combined flexural-torsional ratios. This to address the flexural response in the longitudinal direction of fixed base connection supporting C-Bent columns, and how the flexural properties in terms of strength rotational deformation, and curvature ductility of such a connections are affected by the connection configuration and loading combination.

Research within this paper concerns the connection behaviour, hence strong column weak connection philosophy is followed to ensure that failure will happen in the connection and the column will remain elastic.

\section{Verification Model}

\section{Selection of Model}

The verification model has been selected from international journal of steel structures (ijoss) technical paper entitled "Exposed Column-Base Plate Connections Bending About Weak Axis:II Experimental Study" [11]. The specimen is an exposed-type column-base plate connection sub-assemblage 4-bolts connection as shown in Fig. 3 were tested under the SAC phase II loading protocol for stepwise increasing cyclic test shown in Fig. 4 in the direction of column weak axis. The experimental study investigates the global cyclic performance of specimen and behavior of major connection elements under large column lateral displacement. Table 1 provides material properties of each components of the test specimen. 


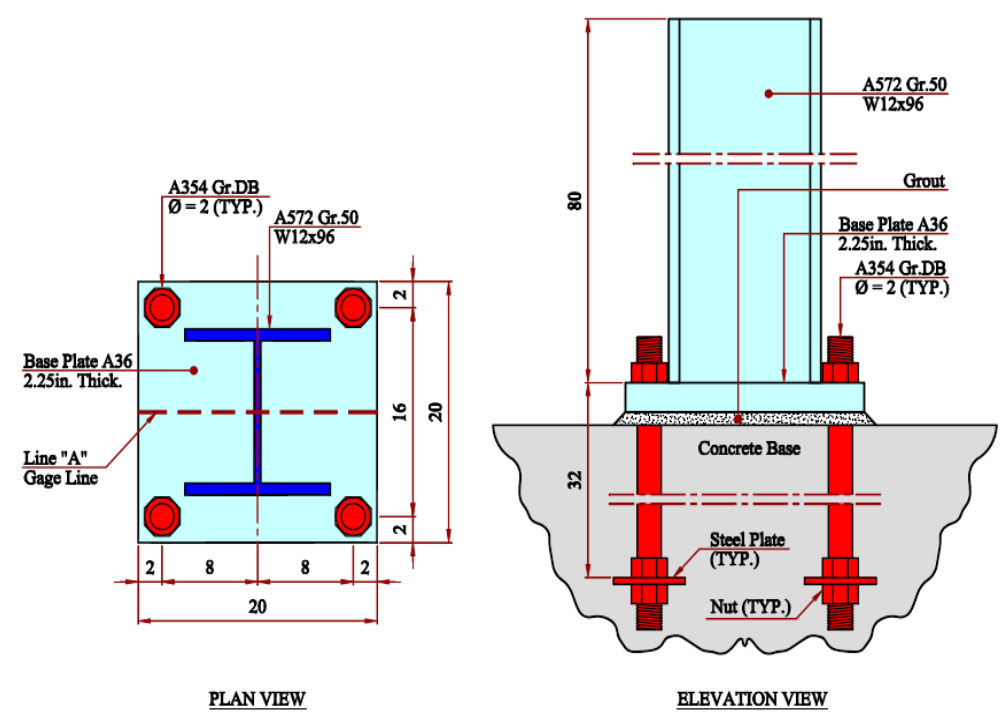

Fig. 3: Details of verification model (All Dim. in inch)

Table 1 Mechanical Properties of Connection Elements

\begin{tabular}{|l|c|c|c|c|}
\hline Component & Steel Grade & $\begin{array}{c}\text { Yield Strength } \\
(\mathrm{MPa})\end{array}$ & $\begin{array}{c}\text { Young's Modulus } \\
(\mathrm{MPa})\end{array}$ & Poisson's Ratio \\
\hline Anchor Bolt & A354 Gr.DB & 897 & 200000 & 0.3 \\
\hline Column & A572 Gr.50 & 344 & 200000 & 0.3 \\
\hline Base Plate & A36 & 248 & 200000 & 0.3
\end{tabular}

\section{Loading Scheme}

The SAC Phase II loading history is applied to ensure the results can be compared with numerous beam-to-column moment connection test results conducted during the SAC investigations. The drift in this loading history is defined as the ratio between the column lateral displacement and its effective height [3].

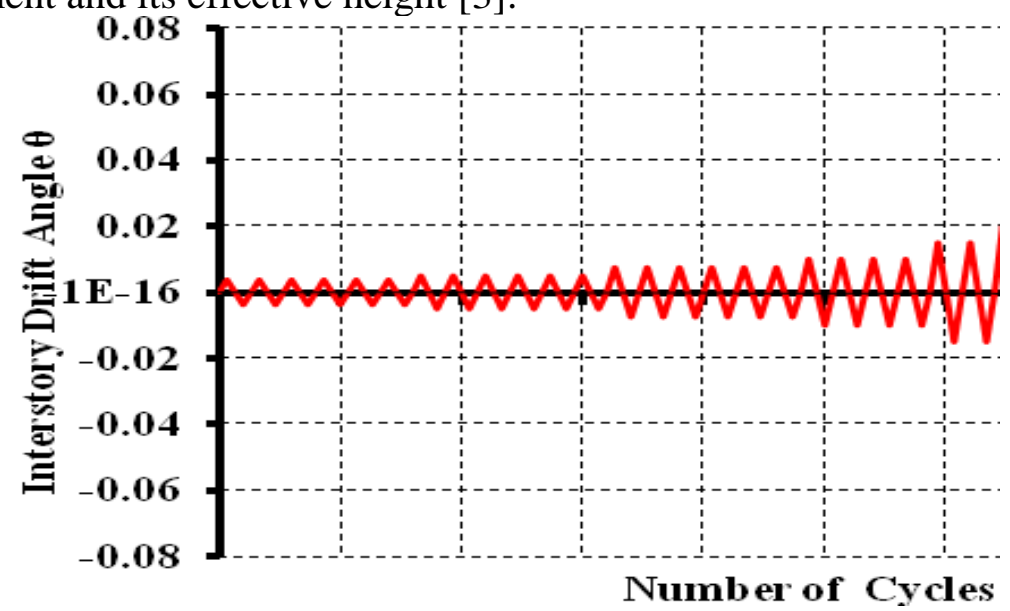

Fig. 4: SAC phase II loading protocol for stepwise increasing cyclic test[3]

\section{Finite element modeling}

For the purpose of the finite element simulation finite element software Strand7 has been used. Strand7 is general purpose finite element analysis system developed by G+D Computing. Four types of elements were adopted from strand7 library to build the verification model which they are: Brick Elements, Plate Element, Beam Element, and Link Element. Brick elements have only three translational degrees of freedom at each node, as per Figure 5 and the companion descriptive Table 2, brick element was used to model bolt, and base plate, 
while for the purpose of modelling column flanges, and column web a Plate/shell element was used. The plate/shell element is the most general type of plate element in that it is a threedimensional membrane and bending element.

One of the most difficult aspects in numerical analysis for column-base plate connections is to model the three major contact interfaces, including the interfaces between (1) the nut and base plate upper surface; (2) the base plate lower surface and the grout; and (3) the base plate soffit and concrete foundation.

Figure 5 and the companion descriptive Table 2 provides finite element modelling for each of the mentioned interface. In order to model force transfer in the above three major contact interfaces, a point contact beam element was adopted such that gap opening, compression only stiffness and friction are achieved, Table 3 describes the work mechanism of each type for point contact beam element found in Strand 7 library.

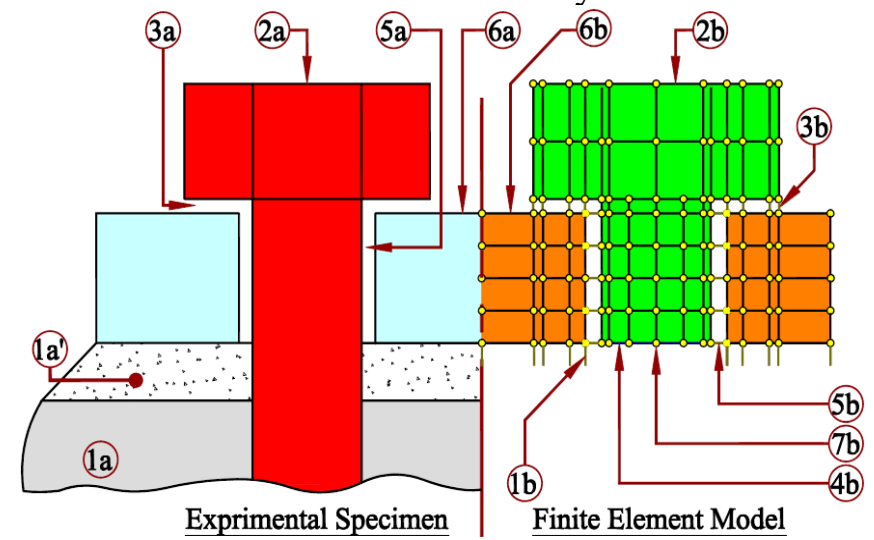

Figure 5: Elements Types for finite element modeling

Table 2 Mechanical Properties of Connection assembly components

\begin{tabular}{|c|c|c|}
\hline ID. & $\begin{array}{c}\text { Experimental Specimen } \\
\text { (a) }\end{array}$ & $\frac{\text { Finite element model }}{(\mathrm{b})}$ \\
\hline 1 & Concrete Base & Normal Contact \\
\hline 1 & Grout & Normal Contact \\
\hline 2 & Bolt & Brick Element \\
\hline 3 & Bolt-Base plate interface & Normal Contact \\
\hline 4 & ----- & Rigid link element \\
\hline 5 & Bolt-Bolt Hole interface & Zero gap contact \\
\hline 6 & Base Plate & Brick Element \\
\hline 7 & ------ & Fixed central point \\
\hline
\end{tabular}

Finally At grout top surface level where the bolt shear planes exist the XYZ rigid link has been assigned between fixed nodes at bolt center and the rest of nodes (which set free) at the mentioned plane as shown in Figure 5. The Rigid Link provides an infinitely stiff connection between two nodes.

Table 3 Point Contact elements structural properties

\begin{tabular}{|l|c|c|c|l|}
\hline & Compression & Tensile & Friction & Active case \\
\hline Zero Gap & Yes & No & Yes & At gap closing \\
\hline Normal & Yes & No & Yes & In compression \\
\hline
\end{tabular}




\section{Material modeling}

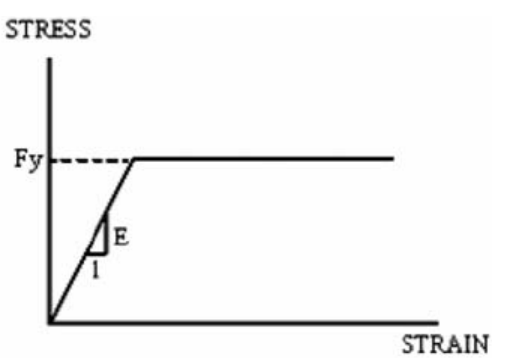

Figure 6: Constitutive relationship for steel

In this numerical study, constitutive relationships of the steel members are simplified by elastic-perfectly plastic bilinear lines as shown in Figure 6, while concrete nonlinearity is not considered and it has been modelled as mentioned previously as a normal contact element.

\section{Analysis results verification}

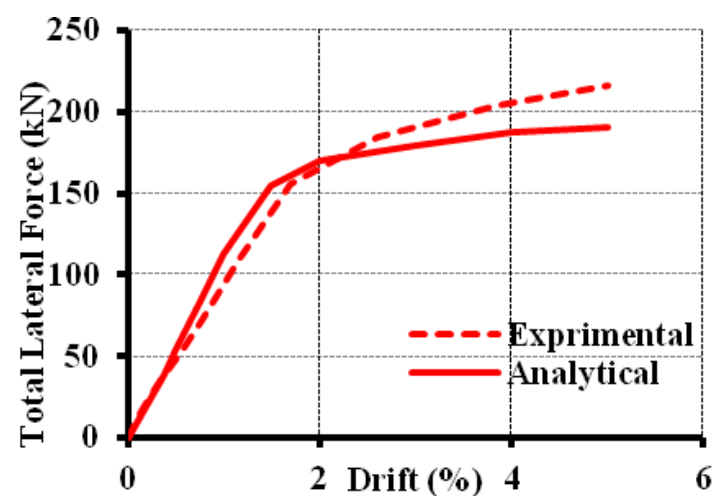

Fig. 7: Comparison Between analytical and experimental results for Lateral Force

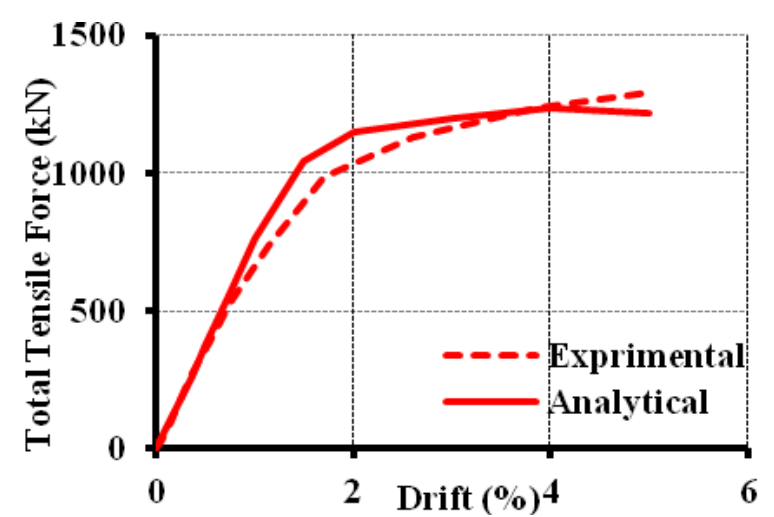

Fig. 8: Comparison Between analytical and experimental results for Tensile Force

With considering all parameters mentioned in the above sections, the analytical results were extracted to be compared with experimental results as per figures Fig. 7, and Fig. 8. By viewing the mentioned figures it is found that analytical results have good agreement with experimental works.

\section{Parametric Study}

Same simulation procedures, modeling techniques / element types, and Material properties mentioned in section 0 shall be followed to build up the analysis models conducted in the parametric study. The following subsections is a detailed demonstration for the factors considered in the numerical parametric study to achieve research objective. Parameters related to loading are inspired from [2] which handled the same topic, however for RC bridge pier. 


\section{Analysis Model Description}

Figure 10 is an isometric detailed view for the analysis model utilized in the parametric study, Figure 10a is a global perspective for the analysis model showing that the model is a box section of center line dimension $900 \mathrm{~mm}$ x $900 \mathrm{~mm}$ and $25 \mathrm{~mm}$ wall thickness forming a double cantilevered pier, with effective height of $7250 \mathrm{~mm}$ measured from the base connection to the C.G of box section, and $1350 \mathrm{~mm}$ length for each cantilever measured from the face of column, and at the end of each cantilever a cyclic loading in the longitudinal direction is applied; this load yields to SAC phase II shown in Fig. 4 with a multipliers as per Table 5 dedicated for each end of the double cantilever column to count for the parametric ratios considered in the research between flexural and torsional seismic action. Also permanent loading conditions are accounted by concentrated axial load and transverse moment that their values are set as per Table 4. While Figure $10 \mathrm{~b}$ is a zoom view for the base connection of stiffened condition showing a full dimension for each component of the connection assembly, similar presentation is introduced for un-stiffened condition as per Figure 10c.

Stiffener thickness utilized is as the same as box section wall thickness $(25 \mathrm{~mm})$; connection is anchored by 10 anchors rods Dia. 65mm with pattern shown in Figure 10b, and Figure 10c, the anchors are arranged such that 5 anchors are placed at the tension side of the permanent transverse applied moment and these bolts shall be entitled as tension side bolts, while the remaining 5 anchors are placed in the opposite side where permanent transverse moment imposes compressive strains and theses bolt shall be referred as compression side bolts. At last base plate dimension is $1230 \mathrm{~mm} \times 1230 \mathrm{~mm}$ with thickness subject to parametric values considered in the analysis.

\section{Base Plate Thickness}

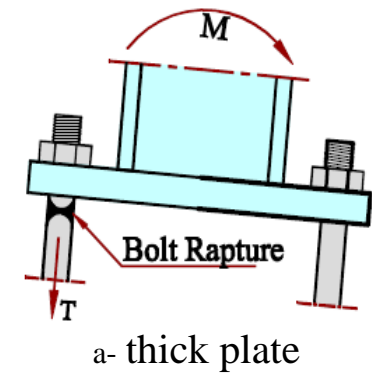

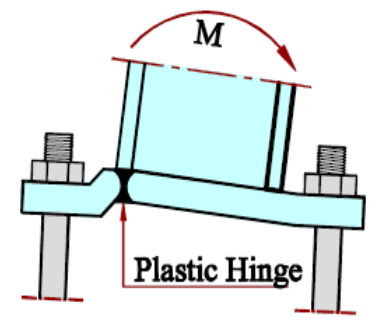

b- intermediate plate

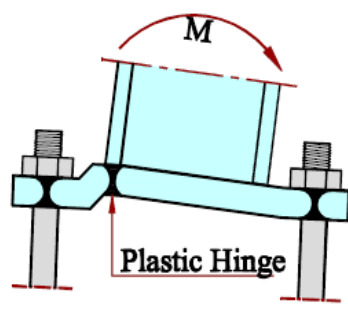

c- thin plate

Fig. 9: Base plate behavior models

As per literature Behavior of base connection is sensitive to the base plate thickness. As illustrated in Fig. 9 the Behavior of base plate is classified for 3 classes according to the expected mode of failure; thick plate behavior, intermediate plate behavior, and thin plate behavior. In this study three parametric values has been adopted to capture as much as possible the expected modes of failure previously mentioned, the selected values shall be $55 \mathrm{~mm}, 75 \mathrm{~mm}$, and $95 \mathrm{~mm}$.

\section{Stiffening condition}

As the vertical stiffener is an essential component in the connection, effect of stiffening condition has been assessed on two levels. First is un-stiffened base connection; Figure 10c, and, the second level is stiffened; Figure 10b. This will address the effect and contribution of stiffening condition on the connection behavior.

\section{Plastic Moment Reserve}

Permanent loads that represents the gravity actions on the base connection are decided to be represented as a ratio from the plastic moment capacity of the column section, several trial has been made to address the appropriate ratio for this purpose, and it was found that giving gravity loading (concentric or eccentric) a cut of $30 \%$ as a consumed share from the plastic moment capacity of the column, will have a noticeable presence on the cyclic behavior of the connection assembly and in the main time does not lead to unintended failure due to over 


\section{FLEXURAL BEHAVIOR OF BASE CONNECTION OF C-BENT COLUMN UNDER COMBINED CYCLIC BENDING- \\ TORSIONAL LOADING}

stress from gravity loading which does not serve the research scope, thus all studied connections assembly shall be analyzed against initial state of stress where $30 \%$ of the column plastic capacity is dedicated to the applied permanent load, while the remaining $70 \%$ of plastic capacity is accounted as reserve strength in the column section.

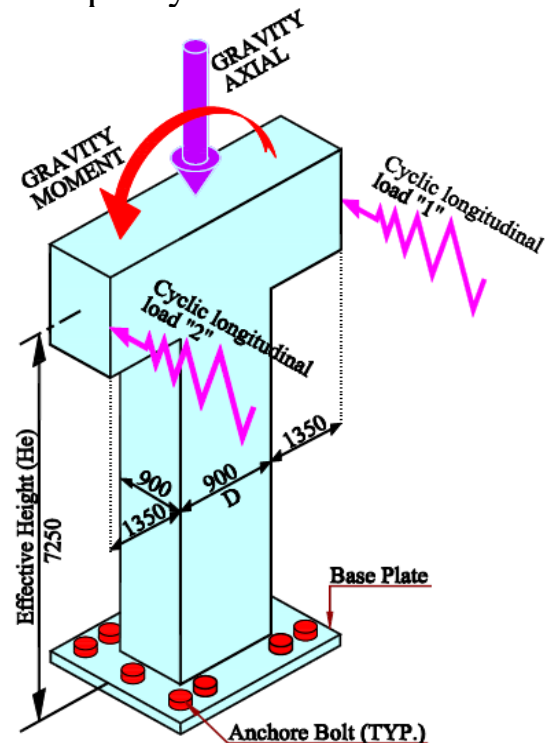

a- Perspective view of the analysis model

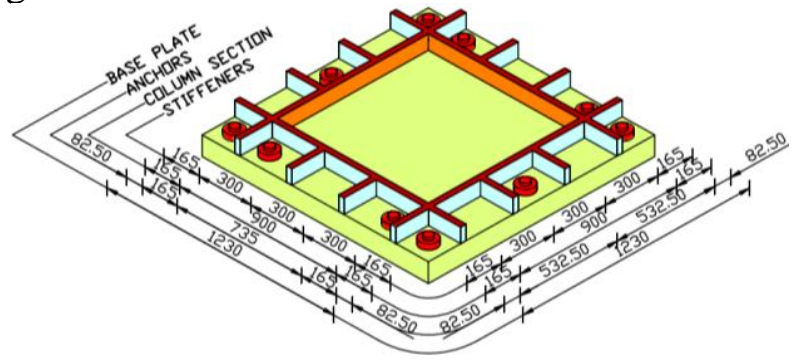

b- Detailed view of stiffened connection

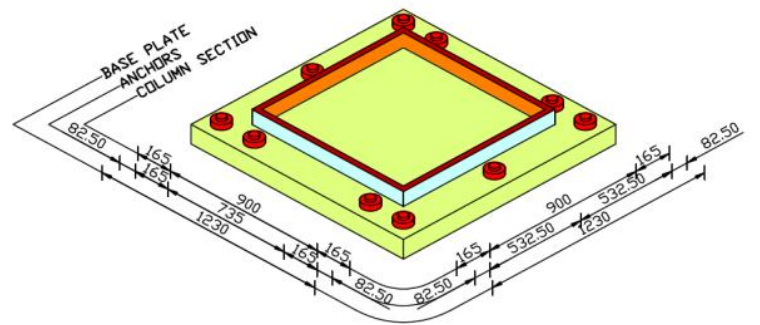

c- Detailed view of un-stiffened connection

Figure 10: Isometric View for the analysis model

\section{Gravity load eccentricity}

Table 4 illustrates the eccentricity "E" of the applied permanent loads, which stated as a relative value of column section dimension " $D$ " shown in Figure 10. Considering what stated in 0 a broad spectrum of axial and flexural loads combination has been addressed such that $30 \%$ of the column plastic moment is occupied by the applied permanent loads that represent gravity load in the real case.

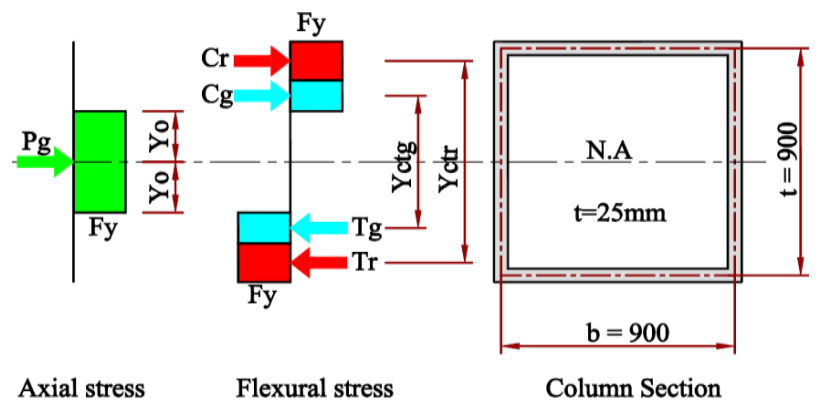

Figure 11: Plastic stresses distribution on column box section

Table 4 Gravity loads eccentricity values

\begin{tabular}{|c|c|c|c|c|}
\hline $\begin{array}{c}\mathrm{E} \\
(\mathrm{mm})\end{array}$ & $\begin{array}{c}\text { Yo } \\
(\mathrm{mm})\end{array}$ & $\mathrm{E} / \mathrm{D}$ & $\begin{array}{c}\mathrm{Mg} \\
(\mathrm{kNm})\end{array}$ & $\begin{array}{c}\mathrm{Pg} \\
(\mathrm{kN})\end{array}$ \\
\hline 0 & 437.5 & 0 & 0 & 15050 \\
\hline 450 & 178 & 0.50 & 2750 & 6110 \\
\hline 1350 & 69 & 1.50 & 3210 & 2378 \\
\hline
\end{tabular}

Figure 11 is a first principle calculation for the plastic moment reserve as a couple forces "Tr", and "Cr" with lever arm "Yctr", while the remaining of stress diagram shall be dedicated to sustain combined axial load "Pg" and gravity moment couple "Tg", and "Cg" as applied permanent loads. 


\section{Rotation-Drift ratio " $r$ "}

A non-dimensional parameter called "rotation-drift ratio", $r$, is introduced here to define the level of combined cyclic bending and torsion as:

$r=\frac{\theta}{\Delta}$

Table 5 Parametric values of " $r$ " and relevant SAC load multipliers

\begin{tabular}{|c|c|c|c|}
\hline$r$ & Load "1" & Load "2" & Remarks \\
\hline 0 & 1 & 1 & Only for reference case of pure transverse moment; section 0 \\
\hline 1 & 1.25 & 0.75 & \\
\hline 3 & 1.75 & 0.25 & \\
\hline 5 & 2.25 & -0.25 & \\
\hline
\end{tabular}

A schematic representation for the analysis model is introduced in Figure 12 to simplify the physical meaning of " $r$ " factor and its relation to the analysis model deformation. As per Figure 12 " $\theta$ " is the column rotation and " $\Delta$ " is the interstory drift angle which is defined by the interstory displacement " $\delta$ " divided by story height "He". $\Delta$ is represented in $\%$ as per Fig. 4, while $\theta$ shall follow the parametric values of " $r$ " found in Table 5 below.

Further in Figure 12 Cyclic load "1" and cyclic load "2" shall be applied with the same frequency of loading scheme provided in Fig. 4 and by the aid of the multipliers listed in Table 5 a combined cyclic torsion and bending shall be imposed such that specified parametric values of the corresponding " $r$ " are achieved.

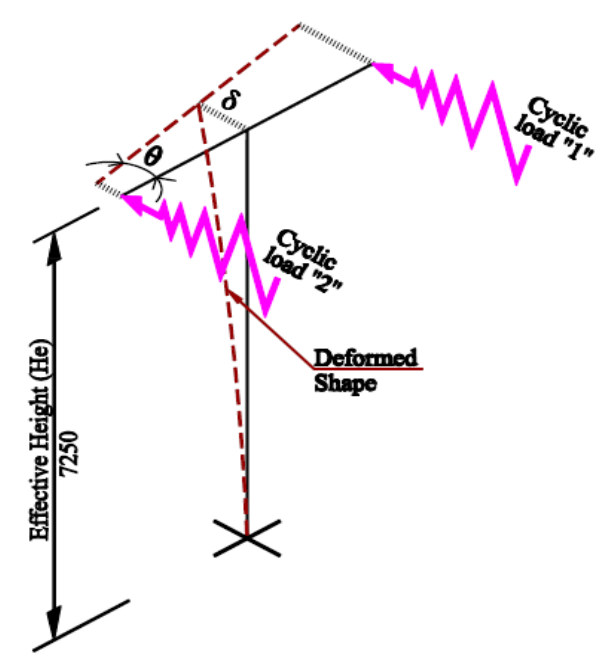

Figure 12: Schematic representation for deformed shape of the analysis model

\section{Results and Discussion}

\section{General}

An analytical study was performed to investigate the cyclic behavior of different configuration of fixed base connection to address the effect of combined cyclic bending and torsional loading on the connection behavior in the presence of different combination of permanent axial load and transverse moment.

Results for the analytical study were categorized into the following factors: (1) strength capacity which featured by flexural yield moment $\left(M_{Y}\right)$ in the longitudinal; (2) deformations that determined by Longitudinal Yield curvature $\left(\Phi_{Y}\right)$; (3) ductility specifically curvature ductility $(\mu)$ in the longitudinal direction; and (4) rotational stiffness for flexural loading $\left(K_{F}\right)$. 


\section{Reference Values}

In order to make sense from the performed analytical study; author preferred to present results as a relative values with respect to corresponding reference amounts, this to expand the research out comings to a broader front rather than being limited to a specific cases considered in this paper, reference values shall be denoted by "0", and shall be classified into two types that illustrated in the next paragraphs.

First type of the reference amounts are extracted from an analysis results of reference connection assembly subjected to specific load cases; the author decided to set one of the already analyzed connection as reference connection assembly, which is base plate of minimum parametric thickness $(55 \mathrm{~mm})$ with un-stiffened configuration; this facilitate tracing connection behavior variation when changing base plate thickness or changing stiffening condition of the assembly. The relevant specified load for the mentioned reference connection is a pure cyclic flexural loading following SAC phase II imposed in the longitudinal direction with zero permanent loads Fig. 13, and this case will offer a reference values for the longitudinal yield moment (MY0), and longitudinal yield curvature ( $\Phi Y 0)$; neutralizing parametric loading conditions, is helpful in reading their effect on the connection cyclic response.

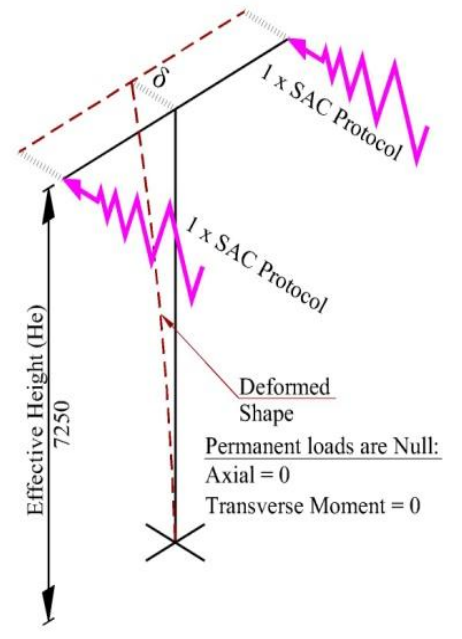

Fig. 13: Analysis reference cases.

The second type of reference values is related to flexural stiffness of cantilevered beam subjected to point load at the tip of cantilever (KF0), the beam shall be a perfect match of column introduced in the study (Material, section properties, and Geometry).

(KF0) shall be considered as per [12] which advised that base connection shall be considered rigid when achieving at least the value of $25 \mathrm{ECIC} / \mathrm{LC}$, where Ec, Ic, Lc are the modulus of elasticity, moment of inertia, and length of column attached to base plate connection respectively. Further [12] also provided a lower bound for the column base stiffness to define the pinned behavior, and the mentioned bound is $0.50 \mathrm{ECIC} / \mathrm{LC}$, however this limit was introduced for the sake of comparison and has no relation to the reference value of the rotational stiffness of the base connection.

Providing connection rotational stiffness as a relative values with respect to (KF0) is a solid reference to evaluate the rigidity / flexibility of the studied connection under different loading conditions.

Finally curvature ductility $(\mu)$ in the longitudinal direction which is defined as the ratio between ultimate curvature angle to the yield curvature angle $(\Phi U / \Phi Y)$ shall be presented as an abstract value, as it makes no sense to follow the relative value concept in such an amount that quantifies non-dimensional term.

\section{Longitudinal yield moment}

Shown performance curves (Figure 14) represent the variation of relative yield moment (MY / MY0) in the longitudinal direction with respect to the parametric values of the base plate thickness. 
As per Figure 14a for un-stiffened configuration; increasing " $r$ " values decreases the yield strength (MY) of the connection, however the mentioned decrease is not considerable. Figure $14 \mathrm{~b}$ reveals that the mentioned trend of the yield longitudinal moment (MY) for un-stiffened configuration is common with stiffened configuration, however the effect of increasing " $r$ " from 3 to 5 exhibited more severe degrading action on the (MY) values than what found in un-stiffened connection, this action is at its peak for concentric loading $(E / D=0)$ recording in average $40 \%$ down grade in the (MY) values, however it becomes less severe for eccentric loading $(\mathrm{E} / \mathrm{D}=0.5,1.50)$ with reduction percentage about $25 \%$ when " $\mathrm{r}$ " increases from 3 to 5 .

By analyzing Figure 14 on the level of eccentricity effect; it was found that for un-stiffened base plate of $55 \mathrm{~mm}$ thick, (MY) values decrease slightly when permanent loads shift from concentric case $(\mathrm{E} / \mathrm{D}=0)$ to eccentric case $(\mathrm{E} / \mathrm{D}=0.5)$, however the said reduction is doubled to reach $28 \%$ for further increase in eccentricity $(\mathrm{E} / \mathrm{D}=1.5)$.

Except the case above a general trend is monitored at " $r$ " values of 1, 3 for the flexural yield variation of the studied connections, this trend is featured by the nature of permanent loads state (eccentric, concentric) and the degree of the eccentricity for eccentric loading. It was noticed that (MY) is reduced by $25 \%$ when eccentricity value increases from $E / D=0$ to $E / D$ $=0.5$, while for even more higher E/D values, connection exhibited same strength, hence the yield strength in the longitudinal direction is affected by the permanent load state whether it is concentric or eccentric irrespective the eccentricity level for eccentric loading. For $r=5$, where torsion failure controls connections provided convergent yield strength values for different $\mathrm{E} / \mathrm{D}$ values.

As extracted from Figure 14, yield strength of connection assembly directly proportioned to base plate thickness, as increasing base plate thickness (tP) boosted the yield moment capacity by $40 \%$ in common, nevertheless for un-stiffened configuration when an eccentric loading with level of eccentricity $\mathrm{E} / \mathrm{D}=0.50$ is applied thickening base plate from $55 \mathrm{~mm}$ to $75 \mathrm{~mm}$ becomes insignificant, while for the same mentioned case extra thickness beyond $75 \mathrm{~mm}$ recovers the previously mentioned enhancing rate $(40 \%)$.
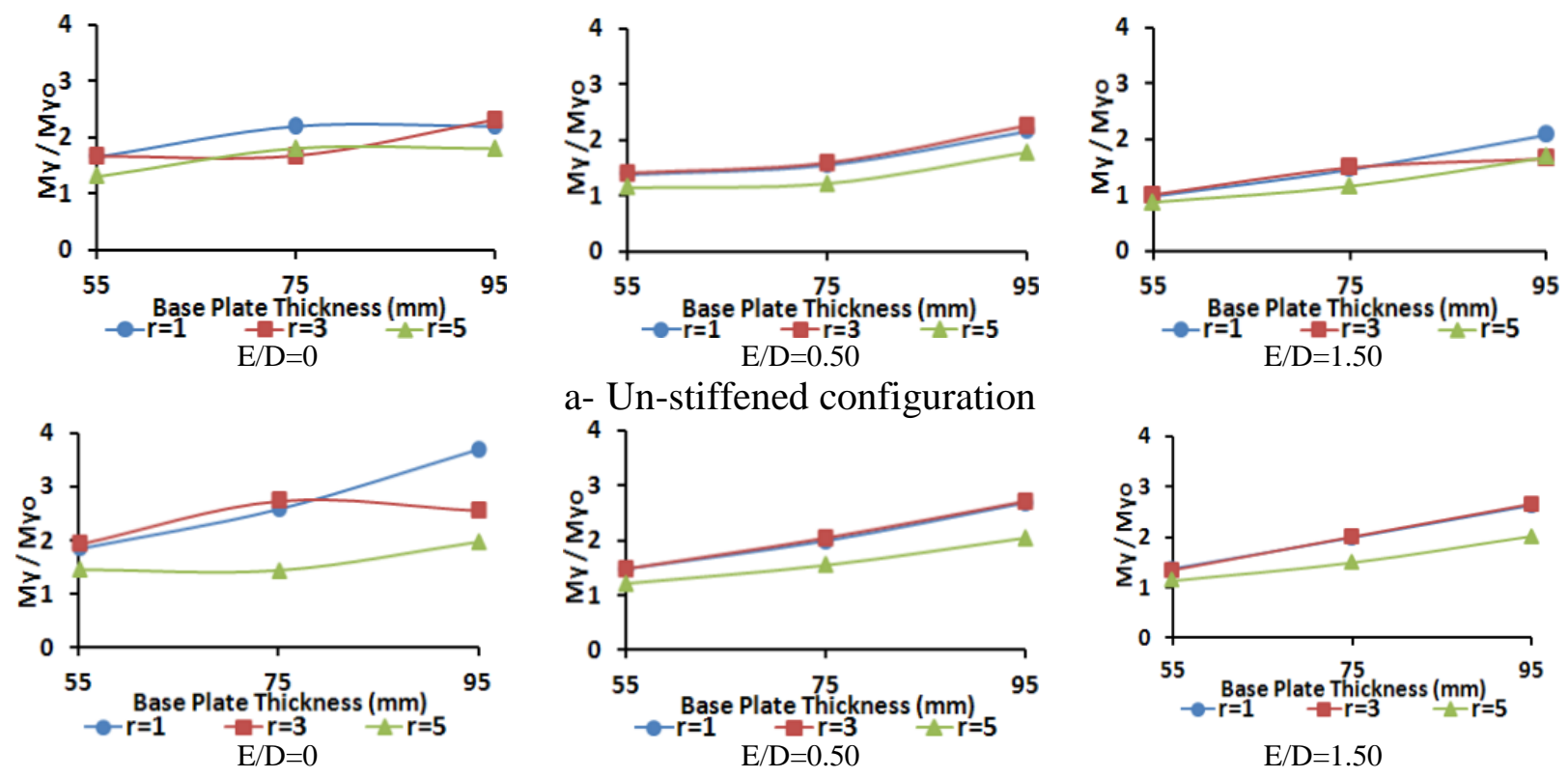

a- Un-stiffened configuration
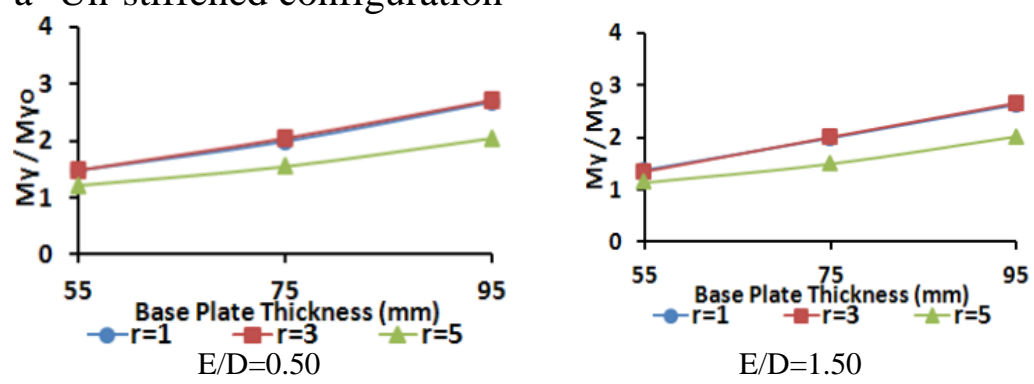

b- stiffened configuration

Figure 14: Relative longitudinal yield Moment variation with base plate thickness

Stiffening condition is also participating in the expected yield strength of the studied connections, when comparing between Figure 14a, and Figure 14b, it is shown that for base plate of 55mm thickness the effect of adding stiffeners is only significant at high eccentricity level $(\mathrm{E} / \mathrm{D}=1.5)$ with improvement ratio about $35 \%$, while the remaining states of the permanent loads no sensible upgrade has been captures in the values of $\left(M_{Y}\right)$, more over it is also found that adding stiffener is also effective for base plate thickness of $75 \mathrm{~mm}$ with 
average rise in $\left(M_{Y}\right)$ of $30 \%$ for different eccentricity levels, in turn of $20 \%$ improvement in the yield capacity for $95 \mathrm{~mm}$ base plate thickness. Privilege of adding stiffener in increasing $\left(M_{Y}\right)$ shrinks by increasing " $r$ " values and expands by increasing eccentricity $(\mathrm{E} / \mathrm{D})$.

\section{Yield Curvature}

Figure 15 is an complementary figure for Figure 14, as it provides the relative yield curvature rotations corresponding to the longitudinal yield moments found in Figure 14 .As per Figure $15 \mathrm{~b}$ for stiffened configuration; increasing " $r$ " values decreases the yield curvature $\left(\Phi_{Y}\right)$ of the connection, however the mentioned decrease is only countable when " $r$ " increase from 3 to 5. Figure 15a reveals that the mentioned trend of the yield longitudinal curvature $\left(\Phi_{Y}\right)$ for stiffened configuration is common with un-stiffened configuration for eccentrically loaded connections, however the effect of increasing " $r$ " from 3 to 5 exhibited more severe degrading action on the $\left(M_{Y}\right)$ values than what caught in the stiffened connection. For concentric loading $(\mathrm{E} / \mathrm{D}=0)$ a reduction of the $\left(\Phi_{Y}\right)$ values recorded its peak down grade stiffened connection.

Connection flexural deformability in the longitudinal direction is affected by the nature of the applied permanent loads. As per figure Figure 15a the curvature capacity at yield for unstiffened connection assembly significantly increases by $70 \%$ in average when changing nature of the applied permanent loading from concentric combination $(E / D=0)$ to eccentric combination $(\mathrm{E} / \mathrm{D}=0.5)$, further increase in the eccentricity level to $\mathrm{E} / \mathrm{D}=1.5$ has no impact on $\left(\Phi_{Y}\right)$ for the un-stiffened plate of $55 \mathrm{~mm}$ thickness, however for thicker plates a slight increase in the $\left(\Phi_{Y}\right)$ values is recorded. Referring to Figure $15 \mathrm{~b}$ to address eccentricity impact on the yield curvature $\left(\Phi_{Y}\right)$ for stiffened connections; it was found that the variation of $\left(\Phi_{Y}\right)$ is inappreciable for eccentric loading step from $\mathrm{E} / \mathrm{D}=0.5$ to $\mathrm{E} / \mathrm{D}=1.50)$, in the other hand shifting loads from concentric state $(\mathrm{E} / \mathrm{D}=0)$ to eccentric state increases curvature of the connection, however with less rate than un-stiffened type. Effect of the permanent load state on the $\left(\Phi_{Y}\right)$ values is almost negligible for $55 \mathrm{~mm}$ base plate, this also applicable for $75 \mathrm{~mm}$ base plate, however at high torsion level $(r=5)$ the stiffened $75 \mathrm{~mm}$ base plate exhibited a $65 \%$ increase due to eccentricity step from $\mathrm{E} / \mathrm{D}=0$, to $\mathrm{E} / \mathrm{D}=0.50$, while for $95 \mathrm{~mm}$ thickness; loading state is gaining more importance on the expected $\left(\Phi_{Y}\right)$ values at $r=3,5$ where switching loading condition just from concentric to eccentric elevated the flexural yield curvature by $60 \%$ in average irrespective the eccentricity level.

As a general trend, increasing base plate thickness $\left(t_{P}\right)$ increases the yield curvature of the connection with variation in the degree of the increase according to the connection configuration and the applied action combinations. For un-stiffened connection as shown in Figure $15 \mathrm{a}$ at $\mathrm{E} / \mathrm{D}=0,1.50$; base plate thickness $\left(t_{P}\right)$ has a neutral effect on the $\left(\Phi_{Y}\right)$, while for $\mathrm{E} / \mathrm{D}=0.50$ increasing $\left(t_{P}\right)$ from $55 \mathrm{~mm}$ to $75 \mathrm{~mm}$ reduced connection curvature at yield by $20 \%$, however further thickening to $95 \mathrm{~mm}$ recovered the mentioned $20 \%$ loss in the $\left(\Phi_{Y}\right)$ values.

For stiffened connections; generally increasing base plate thickness has more appreciable impact on the $\left(\Phi_{Y}\right)$ values more than un-stiffened configuration, also the higher the eccentricity the larger the effect of thickening the base plate on $\left(\Phi_{Y}\right)$. As per Figure $15 \mathrm{~b}$ at concentric permanent loading $(\mathrm{E} / \mathrm{D}=0)$ effect of $\left(t_{P}\right)$ at high torsional actions $(r=3,5)$ on the $\left(\Phi_{Y}\right)$ values is absent, however at low torsion level where $r=1,\left(t_{P}\right)$ directly proportioned to $\left(\Phi_{Y}\right)$ with average increasing rate $35 \%$ for each thickening step of base plate; same increasing rate with slight reduction is monitored for $\left(\Phi_{Y}\right)$ against base plate thickness for eccentrically loaded connection $(\mathrm{E} / \mathrm{D}=0.50,1.50)$.
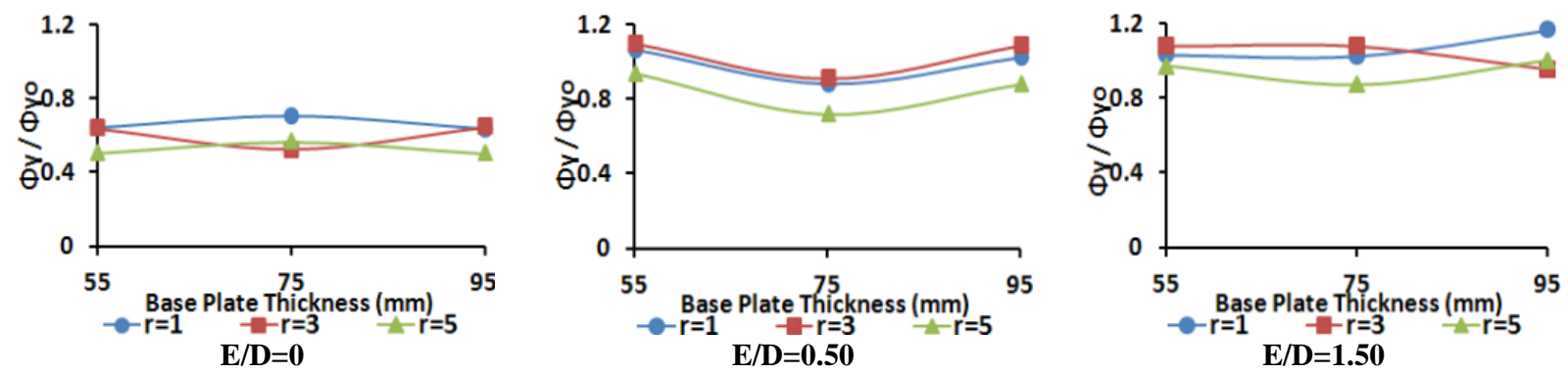

a- Un-stiffened configuration 

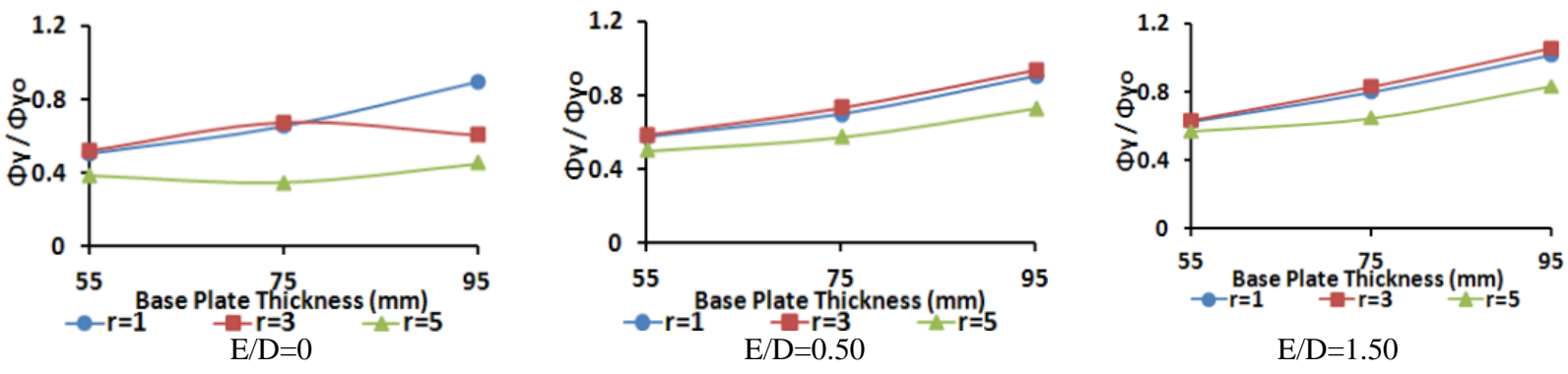

Figure 15: Relative yield curvature variation with base plate thickness

For connections subjected to eccentric loading $(\mathrm{E} / \mathrm{D}=0.50,1.50)$ adding stiffeners has negative consequences on the connection ability to absorb extra rotational demands at yield, as per Figure 15 for $t_{P}=55 \mathrm{~mm}$ sharp reduction of $40 \%$ hit the $\left(\Phi_{Y}\right)$ due to adding stiffener, the severity of the said reduction is getting lesser for thicker base plates, where connection of $75 \mathrm{~mm}$ suffered a reduction in $\left(\Phi_{Y}\right)$ by $25 \%$, while $95 \mathrm{~mm}$ base plate experienced a slight decrease of curvature yielding estimated by $10 \%$ due to adding stiffeners. For concentric loading $(E / D=0)$ same negative impact of adding stiffeners still persists however with inappreciable rate for $r=1,3$, and wide rate ranging between $10 \%$ to $40 \%$ reduction for $r=5$, however in very limited cases an increase in $\left(\Phi_{Y}\right)$ is witnessed as shown in Figure 15a, Figure $15 \mathrm{~b}$ at $\mathrm{E} / \mathrm{D}=0$.

\section{Curvature Ductility}

Based on the study of different connection configuration subject to varieties of loading conditions, Figure 16 provides information for the impact extent of the applied torsion intensity on the connection behavior beyond the elastic range, which questing the connection ductility $(\mu)$.

As per Figure 16 for eccentric loading $(\mathrm{E} / \mathrm{D}=0.50,1.5)$ base plates of $55 \mathrm{~mm}$ and $75 \mathrm{~mm}$ thick exhibited trivial enhancement in the ductility when " $r$ " increase from 1 to 3 , however for the same " $r$ " step the ductility of un-stiffened $95 \mathrm{~mm}$ base plate increased by $15 \%$ for while this increase has been doubled for stiffened $95 \mathrm{~mm}$ base plate. For concentric state $(\mathrm{E} / \mathrm{D}=0)$ a $20 \%$ promotion in the curvature ductility has been recorded when applied torsion increased from intensity corresponding to $r=1$ to the intensity corresponding to $r=3$, except for stiffened $95 \mathrm{~mm}$ base plate connection and un-stiffened $75 \mathrm{~mm}$ base plates; $(\mu)$ decreased by $25 \%$ in average when " $r$ " increased by the same amount.

Increasing torsion application by raising " $r$ " from 3 to 5 , degrade the curvature ductility severely specially for concentrically loaded connection $(\mathrm{E} / \mathrm{D}=0)$, as $(\mu)$ values decreased by $40 \%$ for un-stiffened configuration and $30 \%$ reduction is monitored for stiffened type, further for each parametric increase in the eccentricity level, the recorded reduction is shrinking until reaching its minimum for stiffened $55 \mathrm{~mm}$ base thickness, while for stiffened $95 \mathrm{~mm}$ base plate increasing " $r$ " from 3 to 5 has no impact on the provided $(\mu)$ values.

Figures Figure 16a, and Figure 16b demonstrate in most of the studied cases that what account for the curvature ductility in the longitudinal direction of base connection is the nature of the imposed permanent loads weather it is eccentric or concentric, while the level of eccentricity has a limited impact on the $(\mu)$ values. In more detailed explanation for most of cases connection flexural ductility has suffered considerable reduction when a permanent gravity moment is added to the gravity loads combination irrespective the provided eccentricity; this interpreted to $30 \%$ to $40 \%$ downgrade in the $(\mu)$ values due to shifting E/D from 0 to 0.5 , while $(\mu)$ values for $\mathrm{E} / \mathrm{D}=0.5$ has not been affected when eccentricity increase to the level corresponding to $\mathrm{E} / \mathrm{D}=1.50$.

Irrespective torsion level the $55 \mathrm{~mm}$ un-stiffened base plate connection preserved its ductility between $\mathrm{E} / \mathrm{D}=0$ to $\mathrm{E} / \mathrm{D}=0.50$, however a $35 \%$ loss has been imposed to the connection ductility for extra increase in $\mathrm{E} / \mathrm{D}$, the previous state of $(\mu)$ variation has been witnessed also for un-stiffened $95 \mathrm{~mm}$ base plate at $r=3$; however when stiffeners adopted for $95 \mathrm{~mm}$ thickness base plate the effect of E/D values on the curvature ductility has vanished at $r=3,5$. 


\section{FLEXURAL BEHAVIOR OF BASE CONNECTION OF C-BENT COLUMN UNDER COMBINED CYCLIC BENDING- TORSIONAL LOADING}

As per Figure 16 for the most of the studied case a typical trend is captured for $(\mu)$ values when base plate thickness increases from $55 \mathrm{~mm}$ to $75 \mathrm{~mm}$; where curvature ductility is recording its maximum increase at $r=3$, achieving enhancement between $25 \%$ to $35 \%$ due to base plate thickening, while this enhancement range has lost about $5 \%$ of his weight when " $r$ " dropped to 1 , further for high torsion level $(r=5)$ almost $(\mu)$ values has not been affected by base plate thickening. When $\left(t_{P}\right)$ increases from $75 \mathrm{~mm}$ to $95 \mathrm{~mm}$. two trends are witnessed, first trend belongs to un-stiffened connections at $\mathrm{E} / \mathrm{D}=1.5$, and stiffened connections at $\mathrm{E} / \mathrm{D}$ $=0$, this pattern can be described as follows, at $r=1$, due to base plate thickness increase a slight increase in $(\mu)$ took a place for un-stiffened connections, while a for stiffened connection increasing base plate thickness boosted the $(\mu)$ values significantly by $60 \%$; further when torsion level upgraded to $r=3$, both connection configurations suffered ductility reduction evaluated by $15 \%$ in average, however mentioned reduction has been recovered at $r$ $=5$ to place $(\mu)$ values for $95 \mathrm{~mm}$ base plate $60 \%$ higher than what recorded for $75 \mathrm{~mm}$ base plate. Second pattern found due to increasing $\left(t_{P}\right)$ from $75 \mathrm{~mm}$ to $95 \mathrm{~mm}$ is common for the remaining of the studied cases, and it is shaped by slight increase for $(\mu)$ at $r=1$, this enhancement also reached at $\mathrm{r}=3$ a $25 \%$ increase $(\mu)$ values for un-stiffened detailing, and $35 \%$ increase for stiffened detailing, while for $r=5$ the increase range reaches $65 \%$ to $85 \%$ for un-stiffened configuration and stiffened configuration respectively.

Comparing between provided analysis results for un-stiffened connections as per Figure 16a, and those for stiffened connections shown in Figure 16b; adding stiffeners is not advantageous for the post elastic connection behavior especially for $(\mathrm{E} / \mathrm{D}=0,0.50)$, which in turn reduces the connection curvature ductility $(\mu)$. Adding stiffener for $55 \mathrm{~mm}$ base plate thickness almost has no effect on $(\mu)$ for $\mathrm{E} / \mathrm{D}=1.50$, however adding stiffeners greatly reduced $(\mu)$ values when E/D retrieved to 0.50 , while for concentric loading $(\mathrm{E} / \mathrm{D}=0)$ reduction percentage in $(\mu)$ values dropped to $30 \%$. For $75 \mathrm{~mm}$ thickness the maximum degradation in curvature ductility was at concentric loading condition showing $45 \%$ reduction rate, while for the rest of parametric levels of eccentric loading $(\mathrm{E} / \mathrm{D}=0.50,1.50)$ stiffening connection assembly lead to a convergent values for ductility reduction with ratio of $20 \%$. Finally for the connection of $95 \mathrm{~mm}$ base plate thickness the down grade in the $(\mu)$ values due to following stiffened connection detail was almost the same for all eccentricity levels achieving and average decay in the $(\mu)$ values by $20 \%$ to $25 \%$.
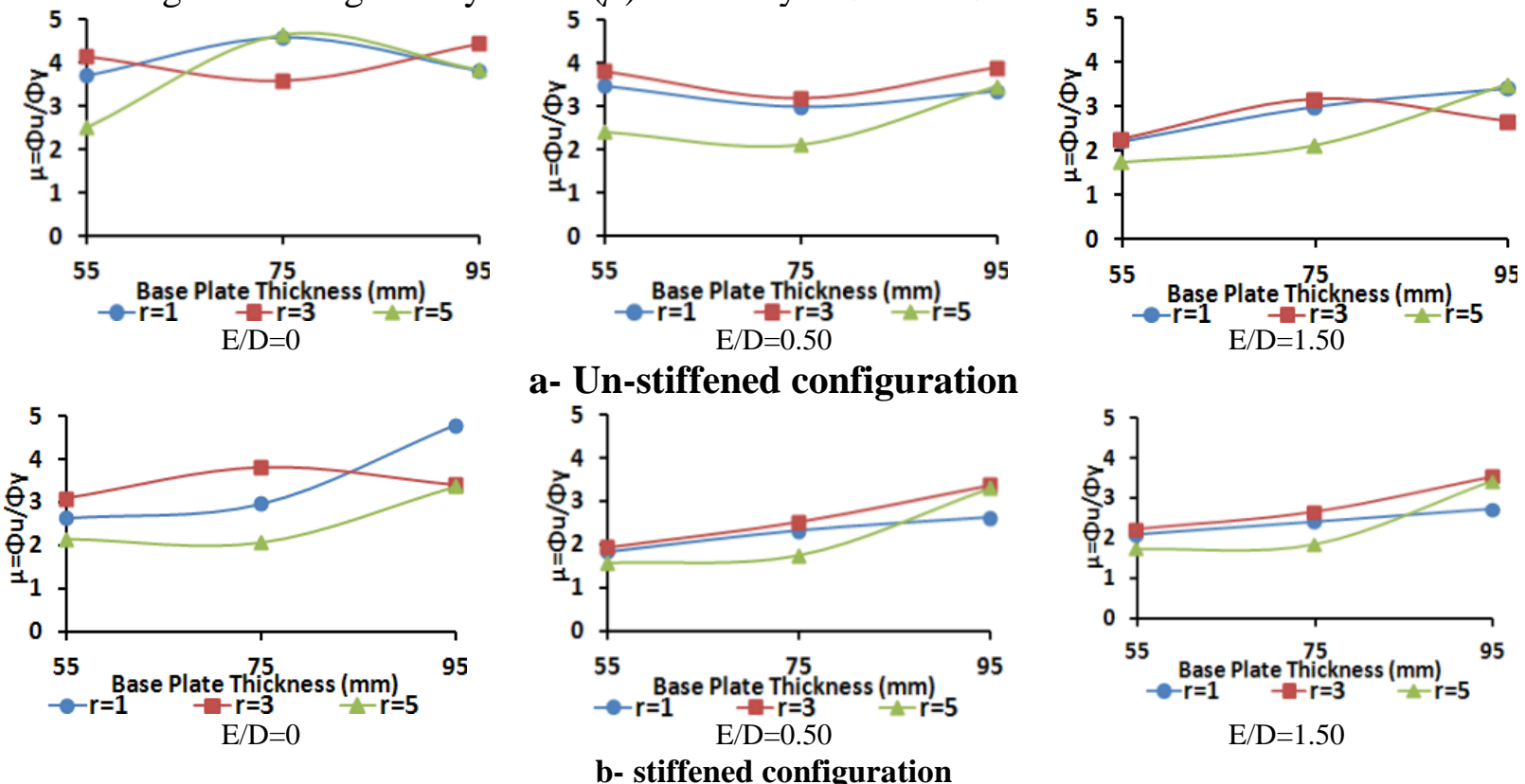

Figure 16: Variation of curvature Ductility in the longitudinal direction with base plate thickness

\section{Rotational stiffness}

Previous sections demonstrated the post elastic response of base connection with respect to the proposed study parameters; this section shall discuss the elastic features of the studied connections in term of flexural rotational stiffness term. 
Figure 17, and Figure 18 are typical moment - curvature envelop curves of the hysteretic cyclic response of the studied connections; From connection configuration point of view as per Figure 17a the initial rotational stiffness $\left(K_{F}\right)$ of the un-stiffened connection is highly dependent on the base plate thickness, however when stiffeners are added Figure 17b to the connection assembly the effect of base plate thickness is neutralized and all parametric values of $\left(t_{P}\right)$ offered similar initial rotational stiffness $\left(K_{F}\right)$.

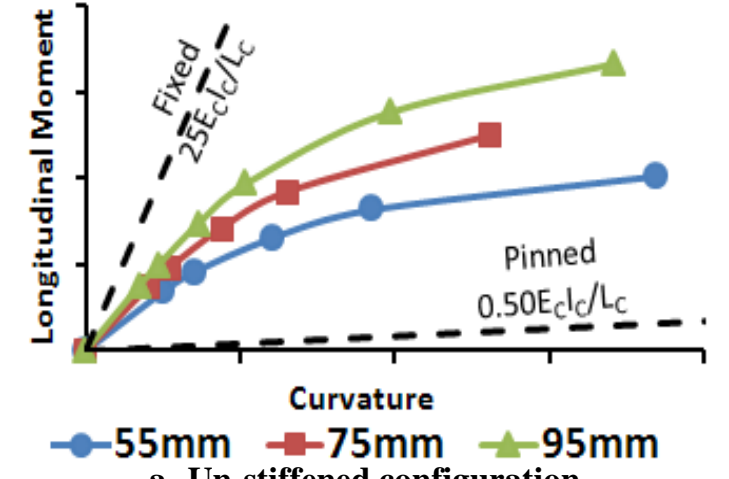

a- Un-stiffened configuration

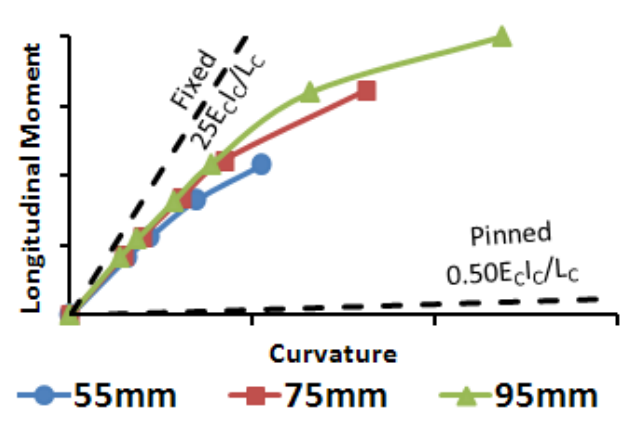

b- stiffened configuration

Figure 17 Typical moment - Curvature response curves against base variation of base plate thickness

In the other hand from loading condition point of view Figure 18a emphasizes the significant effect of the eccentricity level of permanent loading on $\left(K_{F}\right)$, nevertheless applied level of torsion with respect represented by " $r$ " values has no effect on the exhibited $\left(K_{F}\right)$ as illustrated by Figure 18b.

A typical performance curves similar to those introduced in the previous section are provided hereunder in Figure 19 to quantify in numerals the effect of the studied parameters on the rotational stiffness of studied base connection and how far the connection details proposed in this paper from rigid base model.

As a general perspective it can be said that rotational stiffness for studied connection achieved low resistance for flexural rotation, and relaying on it as rigid fixed model is questionable especially for eccentric state of gravity loads. Figure 19 emphasizes this fact where studied un-stiffened connection achieved its top average stiffness for concentric loading $(\mathrm{E} / \mathrm{D}=0)$ recording $75 \%$ of the fixed base model $\left(K_{F 0}\right)$, this average goes down to be set at $35 \%$ of $\left(K_{F 0}\right)$ for eccentric state.

However for stiffened connection concentrically loaded; a high rotation resistance is introduced, that almost simulates the rigid fixed base, while for eccentrically loaded stiffened assembly the connection showed more tendency for rotation that provided connection stiffness hardly reached $55 \%$ of $\left(K_{F 0}\right)$.

As stated above, " $r$ " has no influence on the $\left(K_{F}\right)$ values so, no separate performance curve has been introduced that concerns rotational stiffness variation with respect to " $r$ " values.

Increasing eccentricity level (E/D) of the gravity loads has a deteriorating drawback on the rotational stiffness $\left(K_{F}\right)$ especially for un-stiffened configuration. for un-stiffened configuration, when E/D increases from 0 to 0.50 ; rotational stiffness of decreases $50 \%$ for base plate thickness $55 \mathrm{~mm}$, $45 \%$ for base plate thickness $75 \mathrm{~mm}$, and $40 \%$ for base plate thickness $95 \mathrm{~mm}$; applying additional moments on the connection to raise E/D to 1.5 has less severe deteriorating effect on the $\left(K_{F}\right)$ recording reduction of $30 \%, 20 \%$, and $15 \%$ for base plate thickness $55 \mathrm{~mm}, 75 \mathrm{~mm}, 95 \mathrm{~mm}$ respectively. 


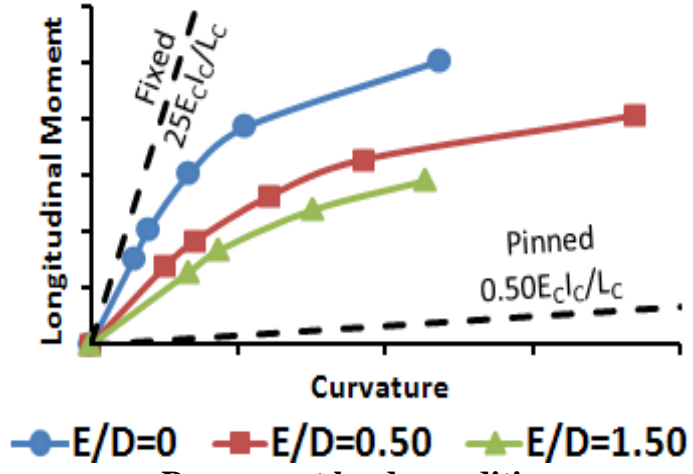

a- Permanent loads conditions

For stiffened configuration a constant decrease of $30 \%$ is monitored for all parametric values of base plate thickness when state of permanent loads shifted from concentric $(\mathrm{E} / \mathrm{D}=0)$ to eccentric $(\mathrm{E} / \mathrm{D}=0.50)$, however recorded reduction losses half its value to be $15 \%$ only when $\mathrm{E} / \mathrm{D}$ goes to 1.50 .

Increasing base plate thickness is effective option to increase connection rotational stiffness (KF) for un-stiffened configuration as the achieved enhancement is remarkable and providing in average about $35 \%$ to $40 \%$ stiffer connections when base plate thickness is upgraded from $55 \mathrm{~mm}$ to $75 \mathrm{~mm}$; further thickening to base plate for $95 \mathrm{~mm}$ still effective however with lower rate than the previously mentioned one with $25 \%$ tops.
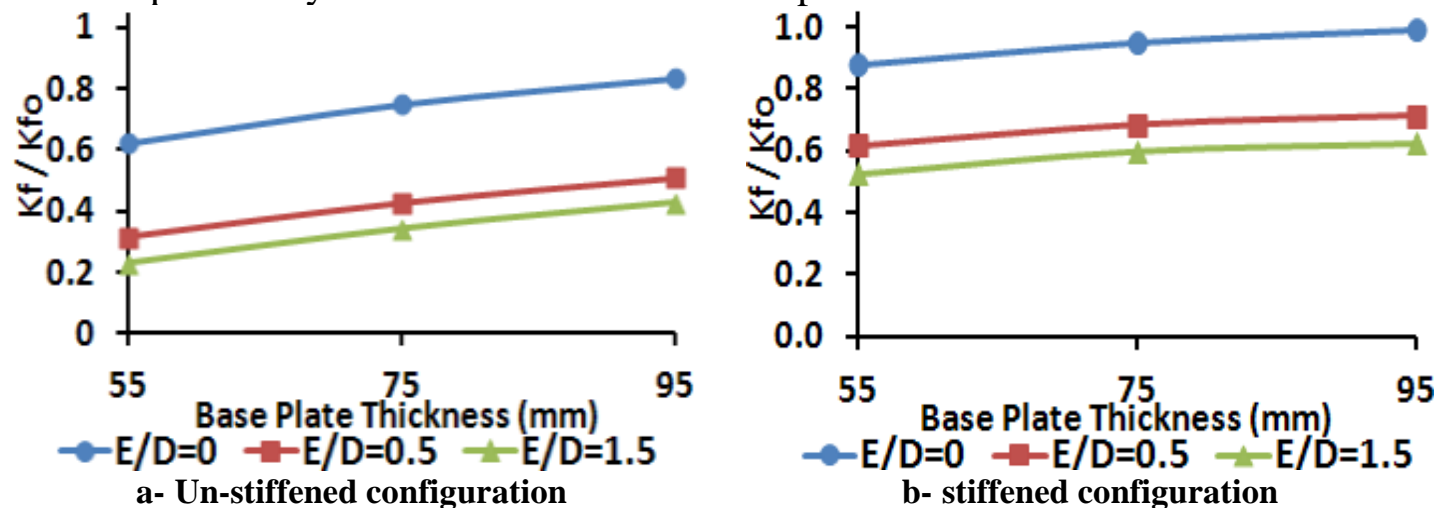

b- stiffened configuration

Adopting stiffened connection rather than un-stiffened type boosts the $\left(K_{F}\right)$ values exponentially especially for thinner plate, and generally for large eccentric permanent loads $(\mathrm{E} / \mathrm{D}=1.50)$. According to $\mathrm{E} / \mathrm{D}$ level the improvement in the rotational stiffness of $55 \mathrm{~mm}$ base plate reached between minimum and maximum boundaries of $50 \%$ at $\mathrm{E} / \mathrm{D}=0$ to $125 \%$ at $\mathrm{E} / \mathrm{D}=1.50$; when $t_{P}=75 \mathrm{~mm}$ the mentioned range for the same corresponding values of E/D is lowered to $25 \%$ as minimum and $75 \%$ maximum, further increase in $\left(t_{P}\right)$ to $95 \mathrm{~mm}$ decreases the efficiency of the stiffeners to obtain stiffer connection; as the top enhancement of $\left(K_{F}\right)$ is $45 \%$ higher than the un-stiffened configuration.

\section{CONCLUSIONS}

The following conclusions can be drawn from the analytical study:

1 -Yield parameters $\left(M_{Y}, \Phi_{Y}\right)$ of un-stiffened base connection is not affected by the combined seismic flexural - torsional action level, however at high seismic torsion to flexure ratio; yield parameters of stiffened connection considerably reduced. Also $\left(M_{Y}, \Phi_{Y}, \& \mu\right)$ is mainly affected by the nature of gravity load whether it is concentric or eccentric, while intensity of gravity moment does not count in the yield parameters. Increasing base plate thickness upgraded the yield moment capacity and the curvature demand appreciably. Adding stiffeners is an effective $\left(M_{Y}\right)$ booster for thinner base plate sections and its privilege in boosting $\left(M_{Y}\right)$ shrinks by increasing seismic torsion stress, and expands by increasing severity of gravity moment stresses; in the other hand stiffeners reduces the 


\section{FLEXURAL BEHAVIOR OF BASE CONNECTION OF C-BENT COLUMN UNDER COMBINED CYCLIC BENDING- TORSIONAL LOADING}

connection tendency for rotation, and hence corresponding yield curvature values shall be sharply reduced.

2-Curvature ductility $(\mu)$ is strongly reduced when the seismic torsional stresses are dominant; however the severity of this effect is reduced for highly eccentric gravity loads. Increasing base plate thickness raises the connection ductility especially for high seismic torsion to flexure ratio. Adding stiffeners is not advantageous for the post elastic connection behavior especially which in turn reduces the connection curvature ductility $(\mu)$.

3 -Increasing initial rotational stiffness $\left(K_{F}\right)$ of the un-stiffened base connection is highly dependent on increasing base plate thickness, however impact of base plate thickness is neutralized for stiffened connection assembly. Increasing eccentricity level of the gravity loading has significant deterioration effect on the $\left(K_{F}\right)$, however the ratio level of combined seismic flexural - torsional action has no effect on the exhibited $\left(K_{F}\right)$. Un-stiffened base connection exhibited high rotational tendency, the alerts undesired excessive seismic rotation, hence adopting stiffened detailing in such a connection is mandatory to approach as much as possible to the rigid fixed base model.

\section{Acknowledgment}

The author gratefully to first and foremost thank God for his giving's and guidance, also a thankfully acknowledgement goes to Professor Dr. Sherif Safar for his endless support. I express my gratitude to Mr. Sayed Ibrahim, Mr. Ibrahim Abdelhaleem and to Dr. Mohamed Helal for their continuous encouragement. Last but not least to my wife who is always there for me.

\section{REFERENCES}

[1] M. Fahmy, "Seismic behavior of moment - resisting steel column bases," Doctor of Philosophy (Civil Engineering) The University of Michigan, Michigan, 1999.

[2] P. Tirasit, K. Kawashima and G. Watanabe, "Effect of combined cyclic flexural - torsional loading on the seismic performance of RC columns," in Earthquakes Engineering Research Institute, 100th Anniversary Earthquakes Conference, San Francisco, Califorenia, 2006.

[3] P. Clark, K. Frank, H. Krawinkler and R. Shaw, "Protocol for Fabrication, Inspection, testing, and Documentation of Beam-Column Connection Tests and Other Expremental Specimens," SAC Joint Venture, Report No. SAC/BD-97/02, Sacramento, California, 1997.

[4] T. C. A., H. T.C. and G. P.R., "Cyclic behavior of structural base plate connnection with fastening failure: component test results," in Tenth U.S. National Conference on Earthquake Engineering, Frontiers of Earthquake Engineering, Alaska, 2014.

[5] B. J., M. G.A., C. J.G. and C. C.G., "Experimental studies on cyclic behaviour of steel base plate connections considering anchor bolts post tensioning," in New Zealand Society for Earthquake Engineering Conference, christchurch, New Zealand, 2014.

[6] C. Yao, K. Shoichi and Y. Satoshi, "Hysteretic Behavior of Exposed Column Bases In Buckling Restrained Braced Frames," in Fifthteenth world conference on earthquakes engineering, LISBON, 2012.

[7] S. E. Abdel Raheem and T. Hayashikawa, "Seismic performance of semi-rigid base connection model of cable-stayed bridge tower," International Jouranl of civil and structural engineering, vol. 3, no. 2, 2012.

[8] D.-Y. Lee, S. C. Goel and B. Stoj, "Exposed Column-Base Plate Connections Bending About Weak Axis: I. Numerical Parametric Study," International Journal of steel structures, 2008.

[9] M. F. JAMES and A. K. LAWRENCE, "Base Plate and Anchor Rod Design," Steel Design Guide 1, AISC, 2006.

[10] A. N. JASWANT and M. C.V.R., "P-V-M Interaction Curves for Seismic Design of Steel Column Base Connections," American Institute of steel construction, Engineering Journal, Third Quarter, 2002.

[11] D.-Y. Lee, S. C. Goel and B. Stoj, "Exposed column-Base Plate Connections Bending About Weak Axis: II Expremintal Study," International Journal of steel structures, 2008.

[12] "EUROCODE 3.: Design of Steel Structures, Part 1 - 8: design of joints," BS EN 1993-1-8, 2005. 